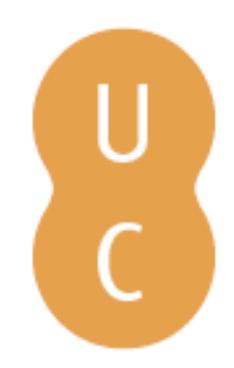

\title{
nommalina
}

\section{Escrever para o futuro: tempo e duração nas estratégias autorais da Marquesa de Alorna (1750-1839)}

\author{
Autor(es): $\quad$ Anastácio, Vanda \\ Publicado por: Imprensa da Universidade de Coimbra \\ URL \\ persistente: URI:http://hdl.handle.net/10316.2/38718 \\ DOI: $\quad$ DOI:http://dx.doi.org/10.14195/978-989-26-1164-8_41 \\ Accessed : $\quad$ 26-Apr-2023 15:40:29
}

A navegação consulta e descarregamento dos títulos inseridos nas Bibliotecas Digitais UC Digitalis, UC Pombalina e UC Impactum, pressupõem a aceitação plena e sem reservas dos Termos e Condições de Uso destas Bibliotecas Digitais, disponíveis em https://digitalis.uc.pt/pt-pt/termos.

Conforme exposto nos referidos Termos e Condições de Uso, o descarregamento de títulos de acesso restrito requer uma licença válida de autorização devendo o utilizador aceder ao(s) documento(s) a partir de um endereço de IP da instituição detentora da supramencionada licença.

Ao utilizador é apenas permitido o descarregamento para uso pessoal, pelo que o emprego do(s) título(s) descarregado(s) para outro fim, designadamente comercial, carece de autorização do respetivo autor ou editor da obra.

Na medida em que todas as obras da UC Digitalis se encontram protegidas pelo Código do Direito de Autor e Direitos Conexos e demais legislação aplicável, toda a cópia, parcial ou total, deste documento, nos casos em que é legalmente admitida, deverá conter ou fazer-se acompanhar por este aviso.

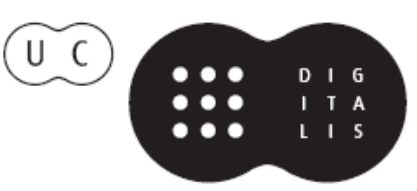


Vanda Anastácio

Universidade de Lisboa / Centro de Estudos Clássicos

\section{ESCREVER PARA O FUTURO: TEMPO E DURAÇÃO NAS ESTRATÉGIAS AUTORAIS DA MARQUESA DE ALORNA (1750-1839)}

Numa carta enviada secretamente a seu Pai em 1772, D. Leonor de Almeida Portugal, a futura Marquesa de Alorna, conta o seguinte episódio:

A maior novidade que há por cá, são dois cometas que aparecem um formidável para o Oriente, e outro mais piqueno para ocidente. Tem ido um grande motim de pronósticos e de parvoíces, porque uns vem espadas no cometa, outros mãos, outros círculos na cauda e para corar houve quem sigurasse tinha lido um letreiro e outros são tão estontiados que sendo grandessíssimo absolutamente o não vem. Não tenho ouvido falar nele senão a frades e ao mano. Os frades, que o observam com o seu moral e teologias muito desinteressam e há poucos dias veio o mundo abaxo sobre mim, porque me disseram que um muito Douto fora buscar as obras de Santo Agostinho para poder falar ao cometa. Respondi eu a isto que me parecia se ele não tinha outras luzes, que estava totalmente inabilitado porque me parecia que Santo Agostinho não era tido pelo melhor astrónomo, que do seu tempo para cá havia coisas muito interessantes para quem queria alguma instrução nessa matéria, e que me persuadia que o Santo nela saberia pouco mais de nada, que eu não conhecia nem podia conhecer todas as suas obras porém pelas suas Confissões, e pela Cidade de Deus conhecia que ele naquela matéria padecia a obscuridade comua daqueles tempos. Foi um aque d'elRei e quase me chamaram Herege. Proguntaram-me se queria eu afectar ou me persuadia que sabia mais que Santo Agostinho, respondi que não; mas que tinha a certeza que sabia algumas coisas modernas que o Santo nesse tempo só com Espírito Profético podia saber 
que se haviam estab’lecer, é pasmar que até pessoas de algum juízo chegassem a tanta preocupação que confundam a piedade com a parvoíce ${ }^{1}$.

Este raciocínio de D. Leonor retoma algumas das ideias-chave do seu tempo. É o caso, por exemplo, da distinção entre os conhecimentos que são do domínio da Teologia e da Fé - ou seja, os princípios da Religião revelada tal como podem ler-se nos escritos de alguém como Santo Agostinho -, e os que são do domínio da razão e do intelecto, como a Astronomia ou as Ciências experimentais. Trata-se de uma reflexão muito presente na correspondência da juventude, que a futura Marquesa formulará de forma lapidar, numa outra carta da mesma época, dizendo: «Em matérias científicas, vale mais o dito de um sábio herege que o de um santo ignorante» ${ }^{2}$.

A distinção entre estes dois tipos de conhecimento permitia a esta jovem, aristocrata e católica, conservar as suas convicções religiosas e, ao mesmo tempo, interessar-se apaixonadamente pelos mais recentes desenvolvimentos da Ciência e da Técnica. Pressupunha, sobretudo, uma perceção particular do tempo e da História: a partir deste relato fica claro que, na opinião da jovem, os conhecimentos progridem com a passagem do tempo, e que o saber do presente é o resultado da acumulação de conhecimentos adquiridos no passado e transmitidos de geração em geração. Neste sentido, a consciência da temporalidade evidenciada nesta carta de D. Leonor está de acordo com a sua contemporaneidade.

Que quer isto dizer?

Quando nos debruçamos sobre a perceção do tempo no século xviII, damo-nos conta de que ocorreu, nesse período, uma mudança profunda em relação ao que se verificava até então. A visão cíclica do tempo, segundo a qual o mundo visível e as criaturas eram vistos como fazendo parte integrante de um ciclo imutável e perpétuo, reforçada durante séculos pelo Cristianismo, foi abalada pela emergência de conceitos novos. Foi o caso da ideia de "progresso", disseminada pela nova crença no impacto positivo das ciências experimentais que se sucederam ao longo do século. Foi também o caso da ideia de "bem-estar dos povos», nascida da melhoria das condições de vida na Europa, que permitiram encarar

1 Carta preservada no Arquivo Nacional da Torre do Tombo, Casa Fronteira n ${ }^{\circ} 118$.

2 Carta preservada no Arquivo Particular do Palácio Fronteira [ref.a: ALCPAI CH-7]. 
a possibilidade de atingir a felicidade na terra (em vez de a situar na vida eterna post mortem). Lado a lado com a visão cíclica do tempo imutável e contínuo, vemos surgir uma visão a que poderíamos chamar progressiva, segundo a qual o tempo era percebido como uma sucessão linear, na qual o presente aparecia como uma versão melhorada do passado, que viria a ser melhorada, por sua vez, no futuro.

A conceção do tempo linear, que encara o tempo como uma dimensão em que as coisas acontecem sequencialmente, foi proposta e explicada por Newton na obra Philosophiae Naturalis Principia Mathematica, de 1687, que foi muito lida no século xvin e reeditada em 1713 e 1726. Mas a reflexão sobre a temporalidade é central no pensamento europeu dos finais do século xvir e do século XVIII e foi tratada, entre outros, por Leibniz, por Locke e por Kant. A conceção do tempo expressa por este último, na Crítica da Razão Pura, contrapõe à perceção linear, exterior do tempo, a ideia de que o tempo, como toda a perceção humana do mundo exterior, tem uma dimensão subjetiva, que lhe é conferida por quem o vivencia ${ }^{3}$.

É preciso que se diga, contudo, que apesar de a crença no progresso e no carácter linear e sucessivo do tempo ter ocupado um lugar central nos grandes debates filosóficos do século, não se impôs de um dia para o outro, nem de modo universal. Repensar o tempo implicava, também, repensar o que está para a além do tempo, ou seja, a Eternidade, Deus, a fé, e o lugar do homem no universo. Ora, o modo de organização das sociedades europeias no Século das Luzes implicava uma perceção particular da temporalidade e da História. Tratava-se de monarquias hereditárias, que se proclamavam de direito divino, cuja antiguidade era vista como um anúncio da sua sobrevivência no futuro. O sistema baseava-se na ideia de uma continuidade imutável e perpétua dos detentores do poder, que seria assegurada pela sua posteridade. A ordem social reproduzia esse modelo, segundo uma hierarquia que era encarada como natural, fundada no sangue, na genealogia e nos privilégios herdados.

Quer dizer que, para poder ser aceite pela maior parte dos pensadores inseridos neste contexto, era preciso que a noção do tempo histórico, encarado como uma

3 Lynn Hunt, «Is Time Historical?», Measuring Time, making History, Budapest-New York, Central European University Press, 2008, pp. 3-46. 
sucessão linear que traria consigo mudanças sucessivas e progrediria em direção ao futuro, fosse conjugada e conciliada com os outros dois grandes sistemas de perceção do real que representavam, para os homens do século Xviı, a Religião e o Estado. E, com efeito, são numerosos os documentos que propõem soluções de compromisso capazes de combinar a perceção teológica de um tempo cíclico e eterno com um tempo mais linear, sucessivo e progressivo.

Em Portugal, por exemplo, em 1721, o erudito Rafael Bluteau definia o conceito de tempo dizendo que "O Tempo he a duração do movimento, \& do repouso, ou hua continuada emanação, \& successiva progressão de muytos instantes» ${ }^{4}$ e, em 1751, a entrada "Tems» da Encyclopédie des arts et des métiers de Diderot e D'Alembert dá conta de uma vontade de conciliação semelhante entre dois modos de perceção do tempo, quando apresenta «le tems actuel» [o tempo actual] como «un ordre succéssif dans une suite continue» [uma ordem sucessiva numa sequência contínua] $]^{5}$.

Mas regressemos a D. Leonor de Almeida Portugal e à sua consciência de viver num tempo melhor e mais sábio do que aquele em que tinha vivido Santo Agostinho. Recordemos que se trata de uma neta dos Marqueses de Távora, executados publicamente em 1759 depois de terem sido acusados de um crime de Lesa-Majestade (a participação no atentado ao rei D. José, a 3 de setembro de 1758). Lembremos que, na sequência desses acontecimentos, D. Leonor foi encerrada com a mãe e a irmã no convento de Chelas durante dezoito anos e que, durante esse tempo, seu pai, D. João de Almeida Portugal, foi encarcerado. Não esqueçamos que, apesar da reabilitação da família em 1777, quando D. Maria I subiu ao trono, D. Leonor teve que lutar, durante toda a sua vida, contra os efeitos da desconfiança e do preconceito nascidos do facto de pertencer a uma família caída em desgraça durante a geração anterior. Que ela tinha consciência de ser um elo numa cadeia temporal de longa duração, entre um passado que continuava a fazer sombra sobre o presente e um futuro no qual projetava as suas esperanças.

\footnotetext{
4 Rafael Bluteau, "Tempo" Vocabulario portuguez latino, áulico, anatómico, architectonico, Bellico, Botanico, Brasilico, Comico, Critico, Dogmatico, etc. autorizado com exemplos dos melhores escriptores portuguezes e latinos, e oferecido a el-rey de Portugal D. João V, Coimbra, no Colégio das Artes da Companhia de Jesus, 1712-1728, p. 81.

5 "Tems" in Encyclopédie, ou dictionnaire raisonné des sciences, des arts et des métiers par une société de gens de lettres, Paris, Briasson, David, Le Breton, Durand, 1751 (texto digitalizado pesquizável acessível em: http://portail.atilf.fr/encyclopedie/)
} 
Finalmente, que foi obrigada a conjugar a sua maneira "moderna» de viver o tempo da sua contemporaneidade, com o ritmo circular e repetitivo da temporalidade imposta pela genealogia, e com a sua vontade de projetar a sua herança familiar e cultural no futuro. Isto é muito evidente quando vemos que se preocupou não só em transmitir os seus títulos de nobreza e os seus bens, mas, também, os seus papéis, que guardou cuidadosamente, a fim de os legar aos seus herdeiros: foi assim que se conservaram, até ao presente, mais de 20000 documentos.

O caso de D. Leonor de Almeida pode ajudar-nos a compreender que não havia no século xvıII, (como também não há hoje, aliás) uma consciência coletiva ou individual, única e uniforme, da temporalidade. Já em 1751, o autor da entrada "tems» da Encyclopédie já referida, assinalava que o tempo pode ter sentidos diferentes segundo as disciplinas que dele se ocupam e terminava considerando-o como uma entidade variável, individual e subjetiva, quando propunha:

Il n'y a point de mesure du tems exactement juste. Chacun a sa mesure propre du tems dans la promtitude ou la lenteur avec laquelle ses idées se succedent, \& c'est de ces différentes vîtesses en diverses personnes, ou dans la même en divers tems, que naissent ces façons de parler, j'ai trouvé le tems bien long ou bien court; car le tems nous paroît long, lorsque les idées se succedent lentement dans notre esprit, \& au contraire. Les mesures du tems sont arbitraires, \& peuvent varier chez les différens peuples; la seule qui soit universelle, c'est l'instant.

[Não há medida do tempo que seja completamente exata. Cada um tem a sua própria medida do tempo na prontidão ou na lentidão com que as suas ideias se sucedem, \& é dessas diferentes velocidades em diversas pessoas, ou na mesma em tempos diversos, que nascem estes modos de falar, achei o tempo bem longo ou bem curto; porque o temo nos parece longo, quando as ideias se sucedem lentamente no nosso espírito, \& o contrário. As medidas do tempo são arbitrárias, \& podem variar entre diferentes povos; a única que é universal, é o instante.]

Em que medida poderão esses dados ajudar-nos à compreensão das obras da Marquesa de Alorna?

Quando lemos os testemunhos dispersos em que D. Leonor de Almeida se refere aos seus escritos, compreendemos que ela atribuía um carácter íntimo e 
autobiográfico a todas as suas produções. Explica repetidamente, por exemplo, que começou a escrever para consolar a mãe e distrair seu pai no tempo da prisão, e que continuou a fazê-lo para se consolar das tristezas que a vida lhe foi causando. A associação entre escrita e biografia está no coração da epígrafe que escolheu para as suas obras: um verso tirado dos Tristia de Ovídio (V, 7, 67), que também figura na edição póstuma da sua poesia: "Carminibus quaero miserarum obliuia rerum" ou seja: "Procuro nos meus poemas esquecer os meus sofrimentos» ${ }^{6}$.

Diga-se que a mole de papéis manuscritos legada pela Marquesa de Alorna à posteridade não se compõe apenas de poemas e que, se todos os seus escritos estão ancorados de algum modo na sua biografia, não o estão todos da mesma maneira, nem supõem todos a mesma consciência da temporalidade. São o reflexo do tempo emocional, ou do tempo psicológico do vivido, percebido segundo uma lógica diferente da do tempo do saber e do da História. Deste ponto de vista, poder-se-ia organizar a produção escrita de D. Leonor a partir da relação que nela se estabelece entre o tempo da narração e o tempo do vivido, e tentar observar de que maneira trabalha ela essa relação através da escrita.

Poderíamos colocar em primeiro lugar a correspondência, escrita no presente sobre um vivido recente. O próprio facto de um mesmo acontecimento ser contado a destinatários diferentes de maneiras distintas, e de a Marquesa se apresentar (e se auto representar) de maneira diferente quando escreve ao pai, à amiga Teresa de Mello Breyner, ou ao irmão, por exemplo, deve alertar-nos para o facto de uma curta distância temporal entre a escrita e o vivido não ser sinónimo de ausência de manipulação da matéria biográfica.

Agruparíamos, depois, os textos autobiográficos em prosa, nos quais D. Leonor narra, na primeira pessoa, episódios particulares ou períodos da sua vida, escrevendo a posteriori acerca do que viveu num passado mais remoto. É o caso, por

\footnotetext{
6 Marquesa de Alorna, Obras Poeticas de D. Leonor d'Almeida Portugal Lorena e Lencastre, Marqueza d'Alorna, Condessa d'Assumar e d'Oeynhausen, conbecida entre os poetas portuguezes pello nome de Alcipe, 6 vols., Lisboa, Na Imprensa Nacional, 1844.

7 Vanda Anastácio «D. Leonor de Almeida: As cartas de Chelas» Correspondências (usos da carta no século XVIII), Lisboa, Colibri - Fundação das Casas de Fronteira e Alorna, 2005, pp. 45-53; Teresa Sousa de Almeida, "Tratados Epistolares do século xviII. Teoria e prática na Correspondência de Chelas" in Vanda Anastácio (coord.), Correspondências (usos da carta no século XVIII), Lisboa, Colibri - Fundação das Casas de Fronteira e Alorna, 2005, pp. 25-32.
} 
exemplo, do relato dos dezoito anos passados no convento de Chelas ${ }^{8}$; do relato do modo como obteve da rainha o cargo de Ministro Plenipotenciário em Viena para o marido', etc. Nesses textos, que podem ser considerados mais propriamente autobiográficos, ao mesmo tempo que D. Leonor fixa por escrito o que se passou, reinterpreta os acontecimentos que viveu à luz do presente. Refaz assim o trabalho da memória, e tenta, não só fazer o balanço do seu passado pessoal a partir do presente da sua emotividade, mas também deixar um testemunho e fixar uma interpretação pessoal desse passado, destinada ao futuro.

Finalmente, teríamos em consideração os textos que se apresentam abertamente como manipulações do vivido, que o transformam e lhe conferem um carácter ficcional e de alcance generalizável. É o caso da sua poesia, marcada por um tom confessional e subjetivo por detrás do qual se distinguem, como em filigrana, as situações dolorosas da sua vida, mas também de outras obras, como, por exemplo, um poema heroi-cómico inacabado no qual, à maneira do Lutrin de Boileau (autor que é citado no corpo do texto) põe em cena as disputas entre duas jovens encerradas num convento, vítimas da Estupidez, do Fanatismo e de Harpias com os traços das freiras de Chelas ${ }^{10}$; de um Conto Moral intitulado La confiance épuisée que conta a história de Eléonore, mulher virtuosa e fiel que sofre em silêncio quando se apercebe de que seu marido, Charles, tem uma amante; de um diálogo entre um Príncipe D. João e uma Princesa de nome Carlota, no qual uma dama da corte, com o nome de Leonor desempenha o papel de pacificadora, etc.

Nos textos deste último grupo, a adoção de modelos literários do passado (e mesmo de um passado muito antigo, uma vez que recorre ao aparato mitológico e aos géneros da Antiguidade, de acordo com a estética neoclássica) e de estruturas formais e estilísticas da ficção e do drama, permitem a D. Leonor não apenas interpretar, no presente, o que viveu no passado mas, também, distanciar-se emocionalmente de momentos demasiado pesados e/ou de experiências

8 Arquivo Particular Palácio Fronteira [ref.a ALC 1]

9 Hernâni Cidade, "Como a Condessa de Oeynhausen obtém a nomeação do marido para enviado à Corte austríaca» in Marquesa de Alorna, Inéditos, Cartas e outros Escritos, Lisboa, Sá da Costa, 1941, pp. 59-71.

10 Vanda Anastácio, "A virtude é uma fantasma nestes sítios» in.: Ana Cristina da Costa Gomes e José Eduardo Franco (coord.), Dominicanos em Portugal. História Cultura e Arte, Lisboa, Aletheia Editores, 2010, pp. 124-141. 
demasiado penosas ou demasiados dolorosas. Essa transformação dos dados da sua história pessoal, e a sua inscrição no universo da ficção permitem à autora alargar o seu alcance simbólico. Podem assim tornar-se experiências didáticas, e até ser úteis a leitores que podem retirar delas lições morais aplicáveis à sua própria vida.

Apesar de ter construído uma reputação de mulher de letras durante a juventude passada no convento, a Marquesa de Alorna publicou em vida apenas algumas traduções e, assim mesmo, só depois dos sessenta anos. A fama de que gozou desde a juventude deveu-se ao facto de ter acesso aos círculos aristocráticos e às redes de eruditos nas quais a poesia circulava manuscrita, entre pares, ao abrigo do olhar vigilante da censura. D. Leonor deu à estampa traduções de textos didácticos, politicamente úteis e edificantes ${ }^{11}$, mas nunca quis imprimir nem a sua poesia, nem os seus escritos pessoais, dizendo que "poucas pessoas entendem os meus escritos, e ainda menos sabem lê-los".

Foi no intervalo entre o vivido e a sua reelaboração simbólica, entre o tempo íntimo e o tempo da sua modernidade, entre o presente da escrita e a sua leitura no futuro, que D. Leonor de Almeida se construiu como autora. É o que exprime num soneto que fez circular entre os habitués do seu círculo de relações quando tinha já cerca de oitenta anos. A Marquesa mostra-se aí, de facto, pronta a reunir as suas obras, na condição de que estas sejam preservadas do julgamento dos seus contemporâneos, e reserva, à posteridade, a tarefa de os publicar:

11 Poética de Horácio e Ensaio sobre a Crítica de Alexandre Pope por uma portugueza, Londres, T. Harper, 1812; De Bonaparte e dos Bourbons, Lisboa, Imprensa Régia, 1814; Paraphrase a vários psalmos, Lisboa, Imprensa Régia, 1817; Ensaio sobre a indifferença em matéria de religião, Lisboa, Imprensa Régia, 1820; Paraphrase dos Psalmos, tomo I, Lisboa, Imprensa Régia, 1833. 


\section{A Jónio que quer que imprima as minhas Obras}

Folhas de louro, e algumas bagas pecas

Basculhei nas aléias do Parnaso;

Este lixo está junto, e por acaso

Entre ele algumas flores menos secas.

Cuidei ter Rouxinóis, achei Marrecas:

Tentada estou de pôr tudo isto raso

Porém, discreto Jónio faço caso

De quanto neste assunto me deprecas.

Arranjarei meus versos, sem que exponha

Sua inocência a Zoilos sem piedade,

Que os leiam mal, e os cubram de vergonha:

E se o que dizes valem na verdade

Livremo-los por ora de Peçonha,

E vão salvos à sã Posteridade ${ }^{12}$.

12 Obras Poeticas de D. Leonor d'Almeida Portugal Lorena e Lencastre, Op. cit. vol. II, p. 177. 


\section{BIBLIOGRAFIA}

ALMEIDA, Teresa Sousa de, (2005), «Tratados Epistolares do século xviII. Teoria e prática na Correspondência de Chelas» in Vanda Anastácio (coord.), Correspondências (usos da carta no século XVIII), Lisboa, Colibri - Fundação das Casas de Fronteira e Alorna, pp. 25-32.

ALORNA, Marquesa de, (1844), Obras Poeticas de D. Leonor d'Almeida Portugal Lorena e Lencastre, Marqueza d'Alorna, Condessa d'Assumar e d'Oeynhausen, conbecida entre os poetas portuguezes pello nome de Alcipe, 6 vols., Lisboa, Na Imprensa Nacional.

(1812), Poética de Horácio e Ensaio sobre a Crítica de Alexandre Pope por uma portugueza, Londres, T. Harper.

(1814), De Bonaparte e dos Bourbons, Lisboa, Imprensa Régia.

(1817), Paraphrase a vários psalmos, Lisboa, Imprensa Régia.

(1820), Ensaio sobre a indifferença em matéria de religião, Lisboa, Imprensa Régia

(1833), Paraphrase dos Psalmos, tomo I, Lisboa, Imprensa Régia.

ANASTÁCIO, Vanda, (2010), “A virtude é uma fantasma nestes sítios» in.: Ana Cristina da Costa Gomes e José Eduardo Franco (coord.), Dominicanos em Portugal. História Cultura e Arte, Lisboa, Aletheia Editores, pp. 124-141.

(2005), «D. Leonor de Almeida: As cartas de Chelas» Correspondências (usos da carta no século XVIII), Lisboa, Colibri - Fundação das Casas de Fronteira e Alorna, pp. $45-53$.

BLUTEAU, Rafael, «Tempo» Vocabulario portuguez latino, áulico, anatómico, architectonico, Bellico, Botanico, Brasilico, Comico, Critico, Dogmatico, etc. autorizado com exemplos dos melhores escriptores portuguezes e latinos, e oferecido a el-rey de Portugal D. João V, Coimbra, no Colégio das Artes da Companhia de Jesus, 1712-1728, p. 80-83.

CIDADE, Hernâni, (1941), "Como a Condessa de Oeynhausen obtém a nomeação do marido para enviado à Corte austríaca» in Marquesa de Alorna, Inéditos, Cartas e outros Escritos, Lisboa, Sá da Costa, pp. 59-71.

HUNT, Lynn, (2008), Measuring Time, making History, Budapest-New York, Central European University Press.

"Tems» in Encyclopédie, ou dictionnaire raisonné des sciences, des arts et des métiers par une société de gens de lettres, Paris, Briasson, David, Le Breton, Durand, 1751 (texto digitalizado pesquizável acessível em: http://portail.atilf.fr/encyclopedie/) 